\title{
On the Maritime PE Reform under the Amended STCW
}

\section{Convention}

\author{
LIU Zhenbin \\ Department of Basic Courses, Qingdao Ocean Shipping Mariners College, Qingdao 266071, China
}

\begin{abstract}
In order to improve the maritime PE quality and improve the physical qualifications of the maritime undergraduates to enable them to provide better service for the shipping industry, this paper makes studies on the maritime PE reform and development under the new requirements of STCW Convention and probes into the difference from other courses. On basis of this, the paper puts forth the necessity and development orientation of the reform in the aspects of objectives, models, contents and evaluation methods.
\end{abstract}

Key words: STCW Convention, physical education, reform, development.

\section{Introduction}

In 2010, the International Maritime Organization approved of the "Manila Amends to the STCW Convention", which provides detailed description of the requirements in the physical and psychological qualifications of the seafarers. For the physical and health standards of the seafarers, the Amendments have more conspicuous requirements, such as in Article B-1/9, the assessment of the "Assessment of minimum entry level and in-service physical abilities for seafarers", the requirements for the physical abilities go as follows, "Maintain balance and move with agility", "step over high sills", "strength, dexterity and stamina to manipulate mechanical devices”, "lift, pull and carry a load (e.g. 18 kg)”, "reach upwards, stand, walk and remain alert for an extended period", while in the "Specification of minimum standard of competence in personal safety and social responsibilities” of Table A-VI/1-4 that requires the seafarers to have swimming ability in suits and floating ability without suits, team spirit, communication and anti-fatigue ability, etc.

Therefore, in accordance with the requirements of Manila Amendments to STCW Convention, we need

Corresponding author: LIU Zhenbin, lecturer, research fields: PE teaching and studies. to view the special cultivation of the seafarers with branding new horizon, to evaluate the present maritime PE with developing points, to update our ideology in reforming the teaching models of maritime PE to create the new PE courses that meet the needs of the special development of the shipping industry in the new era and enforce the health of the would-be seafarers [1].

\section{The Status Quo of Maritime PE Home and Abroad}

Internationally, the studies on the cultivation of the seafarers' physical health started a century ago, while the advanced maritime countries started it even earlier. They based on the institutions to training the sea specific abilities as swimming, diving and survival, etc., making use of the special PE facilities, to strengthen the balance of the students to meet the needs of the work at sea. By the end of the 20th century, PE clubs were popular in foreign countries, where in addition to the basic skills, the students in most occasions improved their maritime qualifications and adaptability. In China, the PE educational reform is being carried out in maritime institutions and has gained achievements, which promoted the development of maritime PE. 


\section{Characteristics of Maritime PE}

The major of maritime technology is special in China and it requires, in addition to the professional knowledge, the qualifications of good health, endurance, cooperation and team spirit, which are the guarantee for the future work at sea.

\subsection{Improvement of Sea Specific Abilities}

As required by the work, the maritime students should be proficient in water affairs and skills (long distance swimming, short distance fast swimming, floating, diving, seaborne salvage, skin dive and boat rowing, etc.). These are the requirements for the survival and profession of the seafarers, which are special, but necessary conditions for seafaring [2].

\subsection{Improvement of Balance Ability}

On account of long term work onboard, the instability will cause dizziness, sickness, vomit and fatigue, etc. Therefore, seafarers are required to have good abilities in balance and anti-dizziness. In all conditions, seafarers should be able to maintain balance, flexible reaction and climbing ability.

\subsection{Maintaining Good Psychological Qualifications}

Seafarers need to work at sea for long periods of time and feel easy to have a sense of exhausting. The sickness of being away from friends and family members gives them psycho pressure. A ship is an enclosed space and is away from information in addition to the boring life. In the long run, it is easy to result in psychological blocks and spiritual sickness. Therefore, seafarers are required to have good psychological qualifications.

\subsection{Keeping the Stability of Career}

Decades of and even the whole life of seafarer's career will bring forth great influence on the physical and mental health of the seafarers. The physical education on campus will not ensure the future health level of the students. This requires that the students come into a habit of a sense of long life PE and it is necessary that the students have command of general health knowledge, methods, sense and habit of scientific exercises. Maritime undergraduates should have special requirements for the cultivation and exercise of health in comparison with other majors and the institutions that should give due attention to the PE and psycho cultivation.

\section{The Necessity and Orientation for PE Reform in Maritime Higher Institutions}

\subsection{The Necessity for Maritime PE Reform}

In accordance with the requirements of STCW Convention, the quality system for seafarers' education and training clearly regulates that, maritime graduates should have good psycho and health qualifications. However, most of the PE teachers come from $\mathrm{PE}$ institutions and are not adequately trained in the maritime PE items as climb and balance and the present sites and facilities are limited to the general ball games. The objectives for maritime PE are not well implemented. The PE classes generally follow the traditional practice, with nothing to do with maritime characteristics. With the rapid development of the shipping industry and perfection of maritime PE quality system, it is necessary and practical to probe into and innovate the maritime PE.

\subsection{The Orientation for Maritime PE Reform}

4.2.1 Reform Orientation for the Teaching Objectives

It is necessary to render analysis on the present status quo of $\mathrm{PE}$ courses in maritime higher institutions and make maritime PE training objectives in light of the "evaluations on the standard health and professional abilities of seafarers" of the amended Convention, "the minimum competence standards on personal safety and social responsibilities" and the maritime PE characteristics mentioned above, provide effective teaching resources training to improve the understanding level of the PE teachers on the amended 
Convention and on the teaching objectives of maritime PE [3].

\subsubsection{Reform Orientation for the Teaching Models}

It is necessary to reform the present teaching models of maritime PE, which imports the advanced teaching concepts from foreign countries, takes the training programs as outdoor team building programs into PE teaching, increases the investment into the construction of sea sports, etc., combined the PE with sea sports to make up for the shortage of PE teaching and cultivate the health abilities and professional qualifications so that the would-be seafarers will adequately enjoy and experience the profit brought forth by the sea sports clubs and rapidly adapt to the work at sea. It is feasible to use PE courses and sea sports clubs as the platform to put forth more humanized teaching and management. It is also necessary to enforce the communication among various majors and higher institutions to achieve the effect of mutual interchange, inter cooperation and mutual improvement via various forms of sea sport contests. Like the 2011 China Seafarers' Skill Contest held in Zhejiang International Maritime Institution organized by China Maritime Safety Administration, it attracted the participation of 400 occupational seafarers and undergraduates from 17 shipping companies and 23 maritime higher institutions, and the contest had listed the physical items as swimming, line heaving and boat rowing which were the important items. This is the typical development orientation for maritime PE.

\subsubsection{Reform Orientation for the Teaching Contents}

Maritime higher institutions should put forth higher requirements for swimming and the programs as cross-country race, mountain climbing and time-travel, etc., to improve the endurance of the undergraduates, to make use of the special facilities as swing-bridge, etc., to train the balance ability, rope and net climbing, to train the climbing ability. We should also use the sea clubs as the platform to renew and increase the present PE teaching facilities, use the sailboat and sampan to improve the integrated health qualifications and improve the sea knowledge and team spirit. We should establish new health facilities to set up health channels to exercise and improve the force, endurance and pliability of the undergraduates. Headed by the MAS, we should enforce the cooperation in maritime PE teaching and research, develop new items and teach methodologies and regularly organize $\mathrm{PE}$ teacher training and improvement, to suit the requirements of the amended Convention and the competitive force of Chinese seafarers [4].

4.2.4 Reform Orientation for the Teaching Evaluations

It is necessary to reform the original evaluation system which puts its eyes only on the health qualifications and traditional PE items and to meet the requirements of the amended Convention, the MAS should regulate unified teaching evaluation standards and testing criteria for seafarers' health conditions to suit the special situations of shipping.

\section{Conclusions}

Maritime technology is a special major in higher education and not only China but also the whole world pays special attention to the cultivation of the talents. The major shoulders the task of educating and training highly qualified seafarers in meeting the requirements of STCW Convention. The amended Convention clarifies the requirements of mental qualifications, social adaptability and responsibility and swimming abilities in the "evaluations on the standard health and professional abilities of seafarers" and "the minimum competence standards on personal safety and social responsibilities". Therefore, it is necessary to reform the present maritime PE to enforce the sea specific abilities, improve the balance abilities, exercise mental abilities and ensure the career stability. Maritime institutions should take these into consideration to reasonably arrange for the $\mathrm{PE}$ teaching.

The reform orientation for maritime PE is to import the advanced teaching concepts of foreign countries 
and on basis of the former situations, to enforce teacher development, to reform the teaching objectives, models, contents and evaluations, to introduce the sea sports clubs into the PE teaching, to renew the present teaching facilities, to develop new facilities, projects and teaching methodologies and enforce the improvement of health qualifications to meet the requirements of the amended Convention and make contributions to the national and international shipping industry.

\section{References}

[1] Manila Amendments to STCW Convention. 2010. Dalian: Dalian Maritime University Press.

[2] Sun, D. R. 2009. Maritime PE and Health. Dalian: Maritime University Press.

[3] Sun, D. R. 2007. "On the Roles of PE in Maritime Education.” Maritime Education and Research.

[4] Zhang, S. 2002. "Discussion on the Arrangement of PE in Maritime Institutions.” Maritime Education and Research. 